University of Nebraska - Lincoln

DigitalCommons@University of Nebraska - Lincoln

Food and Drug Administration Papers

U.S. Department of Health and Human Services

2018

\title{
Prevalence of ADHD in Publicly Insured Adults
}

Yanmin Zhu

University of Florida, Gainesville

Wie Liu

Food and Drug Administration, Silver Spring

Yan Li

University of Florida, Gainesville

Xi Wang

University of Florida, Gainesville

Almut G. Winterstein

University of Florida, Gainesville, almut@cop.ufl.edu

Follow this and additional works at: https://digitalcommons.unl.edu/usfda

Part of the Dietetics and Clinical Nutrition Commons, Health and Medical Administration Commons, Health Services Administration Commons, Pharmaceutical Preparations Commons, and the Pharmacy

Administration, Policy and Regulation Commons

Zhu, Yanmin; Liu, Wie; Li, Yan; Wang, Xi; and Winterstein, Almut G., "Prevalence of ADHD in Publicly Insured Adults" (2018). Food and Drug Administration Papers. 49.

https://digitalcommons.unl.edu/usfda/49

This Article is brought to you for free and open access by the U.S. Department of Health and Human Services at DigitalCommons@University of Nebraska - Lincoln. It has been accepted for inclusion in Food and Drug Administration Papers by an authorized administrator of DigitalCommons@University of Nebraska - Lincoln. 


\title{
Prevalence of ADHD in Publicly Insured Adults
}

Journal of Attention Disorders

2018, Vol. 22(2) 182-190

(C) The Author(s) 2017

Reprints and permissions:

sagepub.com/journalsPermissions.nav

DOI: 10.1 |77//10870547|76988/5

journals.sagepub.com/home/jad

\section{(SAGE}

\author{
Yanmin Zhu', Wei Liu', Yan Li', Xi Wang', and Almut G. Winterstein'
}

\begin{abstract}
Objective: To estimate the prevalence of adult ADHD diagnosis and treatment in U.S. Medicaid beneficiaries. Method: Using outpatient, inpatient, and pharmacy billing records for patients eligible for Medicaid fee-for-service benefits within 29 states from 1999 to 2010, we estimated the annual prevalence of ADHD diagnosis and treatment. Results: The prevalence of ADHD diagnosis increased from 2.20 per I,000 patients in 1999 to 10.57 in 2010. Likewise, prevalence of ADHD treatment increased from 1.95 per I,000 patients in 1999 to 13.16 in 2010. Between 40\% and 65\%, patients had ADHD drug prescription fills 6 months after ADHD diagnosis, whereas $45 \%$ to $55 \%$ of the beneficiaries with an ADHD drug prescription fill had ADHD diagnoses within 6 months before the prescription. Conclusion: In publicly insured adults, the prevalence of ADHD diagnosis and treatment increased dramatically over the years. Approximately half of the diagnosed patients are not treated, whereas half of the treated adults are not diagnosed. (J. of Att. Dis. 2018; 22(2) 182-190)
\end{abstract}

\section{Keywords}

ADHD, central nervous system stimulants, disease prevalence, epidemiology

\section{Background}

ADHD has been considered a childhood neurodevelopmental disorder, characterized by symptoms, including inattention, impulsivity, and hyperactivity (Davidson, 2008; Goldman, Genel, Bezman, \& Slanetz, 1998). In recent years, evidence has shown that in $30 \%$ to $70 \%$ of patients with ADHD during childhood, the disorder persists into adulthood (Lara et al., 2009; Mannuzza, Klein, \& Moulton, 2003; Pary et al., 2002; Silver, 2000). Different from presentation of this disorder in children, symptoms of hyperactivity among adults with ADHD diminish, whereas symptoms of inattention persist and may affect important functions in life. Adult patients with ADHD may also experience interpersonal problems and coexisting psychiatric and substance abuse disorders (Volkow \& Swanson, 2013). Considering the significant consequences of ADHD among adults, it is important to examine the epidemiology of the diagnosis and treatment of ADHD in adults.

Although ADHD is well studied in the pediatric population, little is known about ADHD diagnosis and treatment in adults. Reported prevalence rates of diagnosed ADHD among adults vary across a limited number of available studies, which have used different methodological approaches and different samples of patients (Almeida Montes, Hernández García, \& Ricardo-Garcell, 2007; Faraone \& Biederman, 2005; Heiligenstein, Conyers, Berns, Miller, \& Smith, 1998; Holden et al., 2013; Kessler et al., 2006; Knight et al., 2014; McCarthy et al., 2012; Montejano, Sasané, Hodgkins, Russo, \& Huse, 2011; Simon, Czobor, Bálint, Mészáros, \& Bitter, 2009). Early studies of small sample size estimate the prevalence of ADHD diagnosis mainly by examining self-reported symptoms or via structured interviews based on the Diagnostic and Statistical Manual of Mental Disorders (4th ed.; DSM-IV; American Psychiatric Association [APA], 1994) criteria (Almeida Montes et al., 2007; Faraone \& Biederman, 2005; Heiligenstein et al., 1998; Kessler et al., 2006; McCarthy et al., 2012; Simon et al., 2009). To date, limited number of studies have reported population-based estimates in adults (Holden et al., 2013; Knight et al., 2014; McCarthy et al., 2012; Montejano et al., 2011), and no study has estimated the prevalence of ADHD diagnosis and treatment in adult Medicaid beneficiaries. Furthermore, most population-based studies have required presence of both ADHD diagnosis and treatment to determine the prevalence of the disorder, which may underestimate true prevalence, as treatment discontinuation is common. In terms of the

\footnotetext{
'University of Florida, Gainesville, USA

${ }^{2}$ Food and Drug Administration, Silver Spring, MD, USA
}

\section{Corresponding Author:}

Almut G. Winterstein, Department of Pharmaceutical Outcomes and Policy, College of Pharmacy, University of Florida, 1225 Center Drive, HPNP Building, Rm 3336, P.O. Box 100496, Gainesville, FL 326I0, USA. Email: almut@cop.ufl.edu 
Table I. Numerator and Denominator Definitions for Prevalence Estimates.

\begin{tabular}{|c|c|c|}
\hline Prevalence/percentage & Numerator & Denominator \\
\hline Annual prevalence of ADHD & $\begin{array}{l}\text { Number of patients with } \geq 1 \text { inpatient } \\
\text { or } 2 \text { outpatient ADHD diagnoses }\end{array}$ & $\begin{array}{l}\text { Number of adults with } 12 \text {-month continuous } \\
\text { eligibility in Year } X\end{array}$ \\
\hline Annual prevalence of ADHD drug use & $\begin{array}{l}\text { Number of patients with } \geq I \text { ADHD } \\
\text { prescription claim }\end{array}$ & $\begin{array}{l}\text { Number of adults with 12-month continuous } \\
\text { eligibility in Year } X\end{array}$ \\
\hline $\begin{array}{l}\text { Percentage of patients who had } \\
\text { ADHD prescription claims } 6 \text { months } \\
\text { after ADHD diagnosis }\end{array}$ & $\begin{array}{l}\text { Number of patients with } \geq 1 \text { ADHD } \\
\text { prescription claim within } 6 \text { months of } \\
\text { follow-up }\end{array}$ & $\begin{array}{l}\text { Number of eligible ADHD patients with } \\
\text { 6-month continuous eligibility after ADHD } \\
\text { diagnosis in the first half of Year X }\end{array}$ \\
\hline $\begin{array}{l}\text { Percentage of patients who had } \\
\text { ADHD diagnosis } 6 \text { months before } \\
\text { their ADHD prescription claim }\end{array}$ & $\begin{array}{l}\text { Number of patients with } \geq I \text { in- and } \\
2 \text { outpatient ADHD diagnoses } 6 \\
\text { months before prescription claim }\end{array}$ & $\begin{array}{l}\text { Number of eligible patients with 6-month } \\
\text { continuous eligibility } 6 \text { months before ADHD } \\
\text { prescription claim in the second half of Year X }\end{array}$ \\
\hline
\end{tabular}

prevalence of ADHD treatment among adults, majority of the previous studies only reported prevalence of treatment in young adults (age $\leq 20$; Barry, Martin, \& Busch, 2012; Johansen, Matic, \& McAlearney, 2015; McCarthy et al., 2009). Only one study reported ADHD treatment rate in adults aged 20 years and older (Castle, Aubert, Verbrugge, Khalid, \& Epstein, 2007).

To address the gaps in the existing literature, the goal of this study was to estimate the prevalence of diagnosed adult ADHD and its treatment in U.S. Medicaid beneficiaries, as well as to examine proximate relationships between prescribing ADHD medications and ADHD diagnosis.

\section{Method}

\section{Study Design}

We conducted a repeated cross-sectional study using Medicaid Analytic eXtract (MAX) files of 29 states to identify all adult Medicaid beneficiaries in fee-for-service (FFS) and primary care case management (PCCM) plans aged 18 to 64 years. The MAX data are a set of patientlevel data files that provide monthly information on patients' Medicaid eligibility, demographics, diagnoses, and medical procedures performed at outpatient and inpatient settings as well as medication dispensing records submitted for reimbursement.

\section{Definitions}

ADHD patients were identified based on having at least one inpatient or two outpatient visits with International Classification of Disease, Version 9, Clinical Modification (ICD-9-CM) diagnosis code of 314.xx (314.00-attention deficit disorder without mention of hyperactivity, 314.01attention deficit disorder with hyperactivity, 314.1-hyperkinesis with developmental delay, 314.2-hyperkinetic conduct disorder, 314.8 - other specified manifestations of hyperkinetic syndrome, and 314.9-unspecified hyperkinetic syndrome) in each specific study year.
ADHD medication use was determined based on having at least one prescription fill record of an ADHD medication. ADHD medications included all dosage forms of methylphenidate, mixed amphetamine salts, pemoline, and the nonstimulant medication atomoxetine.

\section{Statistical Analysis}

We report four estimates involving ADHD diagnosis and treatment using different eligibility requirements, and numerator and denominator definitions (Table 1). For each year from 1999 through 2010, we identified all individuals 18 to 64 years old who were continuously enrolled in Medicaid for the entire 12 months of the measurement year (e.g., from January 1-December 31, 2001). The annual prevalence of ADHD was then calculated as the proportion of eligible patients who had at least one inpatient or two outpatient service claims with ICD-9-CM code 314.xx. The annual prevalence of ADHD medication use was calculated as the proportion of eligible patients who had at least one pharmacy claim for an ADHD medication in the study year. We stratified estimates of ADHD diagnosis and ADHD medication use prevalence by age and gender, and the prevalence of ADHD medication use by methylphenidate, mixed amphetamine salts, and atomoxetine preparations.

To estimate the prevalence of treatment in patients with diagnosed ADHD, we identified patients who had at least one inpatient or two outpatient service claims with ICD9-CM code 314.xx in the first half of the calendar year (i.e., January 1-June 30). We then followed these patients for 6 months starting from the date of their ADHD diagnosis to determine the proportion of patients who had at least one pharmacy claim for an ADHD medication during the follow-up period. In each annual cohort, eligible patients were required to have at least 6 months of continuous eligibility after the date of their first ADHD diagnosis. Reversing the approach of the previous analysis, we also estimated the proportion of patients who had at least one ADHD diagnosis in the 6-month period before their first dispensing of an ADHD medication in the second half of a calendar year 
Table 2. Demographic Characteristics of Study Samples by Year.

\begin{tabular}{|c|c|c|c|c|c|c|c|c|c|c|c|c|}
\hline \multirow[b]{2}{*}{ Characteristics } & \multicolumn{12}{|c|}{ Year } \\
\hline & 1999 & 2000 & 2001 & 2002 & 2003 & 2004 & 2005 & 2006 & 2007 & 2008 & 2009 & 2010 \\
\hline Sample size $(n)$ & $1,952,942$ & $2,035,380$ & $2,178,294$ & $2,171,520$ & $2,571,952$ & $2,462,090$ & $2,275,483$ & $|, 775,43|$ & $1,437,463$ & $1,342,189$ & $1,288,942$ & $1,313,374$ \\
\hline Age (\%) & 39.75 & 39.86 & 39.21 & 39.23 & 39.22 & 39.12 & 39.03 & 40.29 & 40.39 & 39.92 & 39.86 & 39.43 \\
\hline $18-25$ & 18.36 & 18.05 & 19.79 & 19.33 & 19.66 & 20.00 & 20.26 & 18.67 & 19.12 & 20.14 & 19.10 & 19.75 \\
\hline $26-35$ & 21.62 & 21.27 & 21.74 & 22.01 & 21.87 & 22.05 & 22.27 & 19.72 & 19.33 & 20.16 & 21.40 & 22.30 \\
\hline $36-45$ & 22.84 & 23.14 & 22.59 & 22.86 & 22.27 & 21.71 & 21.06 & 20.44 & 19.45 & 18.66 & 19.10 & 18.63 \\
\hline $46-55$ & 19.41 & 20.05 & 19.76 & 19.98 & 20.30 & 20.49 & 20.66 & 23.11 & 23.29 & 22.89 & 22.91 & 22.61 \\
\hline 55 and older & 17.76 & 17.48 & 16.12 & 15.82 & 15.90 & 15.75 & 15.74 & 18.06 & 18.80 & 18.16 & 17.49 & 16.70 \\
\hline \multicolumn{13}{|l|}{ Gender (\%) } \\
\hline Male & 35.08 & 35.16 & 34.22 & 34.89 & 34.96 & 35.14 & 35.11 & 37.90 & 38.55 & 38.35 & 39.33 & 39.88 \\
\hline Female & 64.92 & 64.84 & 65.78 & 65.11 & 65.04 & 64.86 & 64.89 & 62.10 & 61.45 & 61.65 & 60.67 & 60.12 \\
\hline
\end{tabular}

(i.e., July 1-December 31). Thus, in each calendar year, we required eligible patients to have at least 6 months of continuous enrollment before their first ADHD treatment pharmacy claim.

SAS Version 9.4 (SAS Institute, Cary, North Carolina) was used to perform the data management and statistical analyses. The study was approved by the Institutional Review and Privacy Boards at the University of Florida and the Centers for Medicare \& Medicaid Services.

\section{Results}

From 1999 to 2010, we identified approximately 1,288,942 to $2,571,952$ eligible adults in each year, with $34.22 \%$ to $39.88 \%$ females and the average age ranged from 39.03 to 40.39 years (Table 2). The prevalence of adult ADHD diagnosis increased approximately fivefold from 2.20 per 1,000 patients in 1999 to 10.57 per 1,000 patients in 2010 (Figure 1). Likewise, the prevalence of ADHD treatment increased considerably from 1.95 per 1,000 patients in 1998 to 13.16 per 1,000 patients in 2010 (Figure 1). Notably, in the later study years, the annual prevalence of ADHD treatment use surpassed the ADHD prevalence. Overall, the prevalence estimates of ADHD diagnosis and ADHD medication use increased across all age groups from 1999 to 2010 (Figures 2 and 3). Prevalence of both diagnosis and medication use showed a consistent age trend with the largest prevalence in younger age groups. Compared with females, male patients showed higher prevalences of both $\mathrm{ADHD}$ diagnosis and medication use, but the prevalence rate ratio for females comparing prevalence in 2010 to prevalence in 1999 was slightly higher than that of males, with 5.6 versus 3.9 for ADHD diagnosis and 7.6 versus 5.9 for ADHD medication use (Figure 4).

Comparing utilization pattern of the various ADHD medications, the prevalence of methylphenidate use increased from 1.21 per 1,000 patients in 1999 to 4.50 per 1,000 patients in 2010 , whereas the prevalence of mixed amphetamine salts use increased disproportionally from 0.50 per 1,000 patients in 1999 to 6.98 per 1,000 patients in 2010 (Figure 5). The prevalence of atomoxetine use

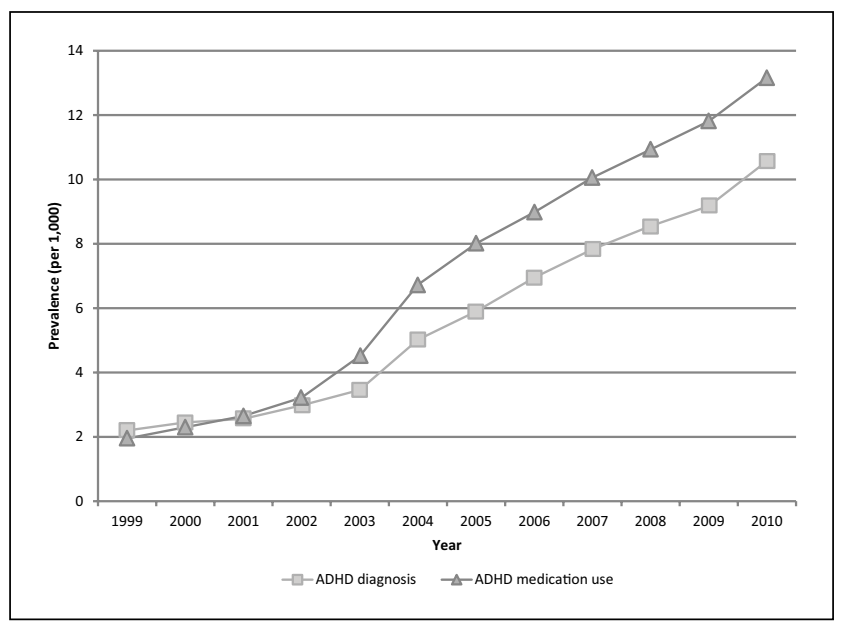

Figure I. Annual ADHD diagnosis and medication use prevalence among adults.

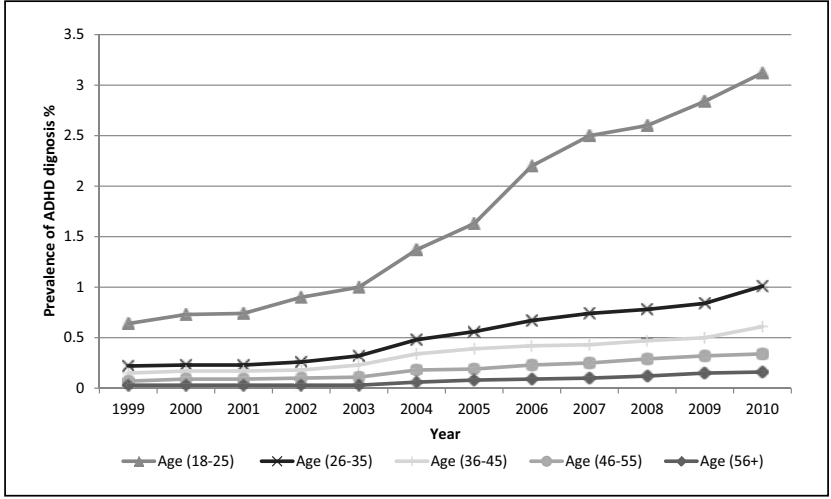

Figure 2. Annual ADHD diagnosis prevalence among adults by age groups.

increased from 0.90 per 1,000 patients in 2003 to a peak with 2.23 per 1,000 patients in 2005 , which was followed by a decrease to 1.68 per 1,000 patients in 2010 .

Over the study period, approximately $40 \%$ to $65 \%$ of patients with an ADHD diagnosis in the first half of the 


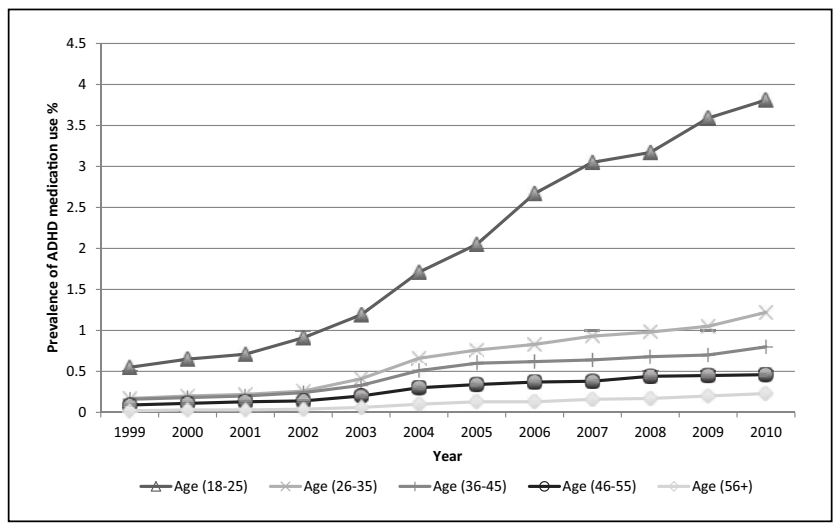

Figure 3. Annual ADHD medication use prevalence among adults by age groups.

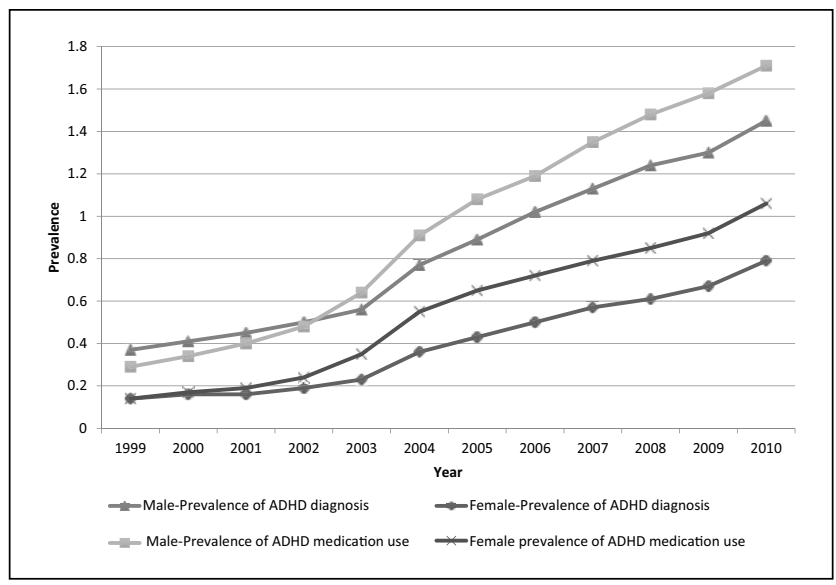

Figure 4. Annual ADHD diagnosis and medication use prevalence among adults by gender.

calendar year had at least one ADHD prescription fill claim in 29 U.S. states. Likewise, about $44 \%$ to $52 \%$ of all patients who filled an ADHD prescription had at least one inpatient or two outpatient service claims with a diagnosis of 314.xx during the 6 months before their ADHD prescription (Figure 6). Both percentages increased over the years.

\section{Discussion}

This study examined the prevalence of ADHD diagnosis and treatment among adult Medicaid beneficiaries. The study results highlight four important insights in ADHD diagnosis and medication use among adults. First, in this study, the prevalence estimates of ADHD diagnosis were about twice of the estimates in previous studies using administrative databases in various geographic areas of the United States (Knight et al., 2014; Montejano et al., 2011). In a U.S. commercial population with employer-sponsored insurance, the estimated prevalence was about 1.20 to 4.02 per 1,000 patients from 2002 to 2007 (Montejano et al., 2011). The other study reported the prevalence of ADHD in a managed care population at 3.12 to 4.15 per 1,000 patients from 2006 to 2009 (Knight et al., 2014). This could be partially explained by the different study populations. Compared with privately insured patients, Medicaid beneficiaries in general are of lower social economic status, which has been shown to be one of the causes or the consequences of mental disorders (Hudson, 2005; Miech, Caspi, Moffitt, Wright, \& Silva, 1999). However, the higher prevalence rate we observed may be in part explained by different case definition such as the requirement to have both a diagnosis and pharmacological ADHD treatment in the previous studies (Knight et al., 2014). To avoid underestimating the prevalence caused by untreated ADHD among adults, we did not use prescription claims in addition to diagnosis claims to determine manifestation of ADHD. When analyzing the proximity of diagnosis and treatment, we observed that only about $40 \%$ to $65 \%$ of the diagnosed patients had ADHD treatment within 6 months after diagnosis, which confirmed our concerns for untreated adult ADHD. Our findings provided insights on the measurement of ADHD diagnosis among adults using automated databases in future research, which should take how adult ADHD and treatment were diagnosed and treated in the actual clinical setting into consideration. During the study periods of the existing studies on adult ADHD, including this study, the diagnosis of adult ADHD was guided by the $D S M-I V$. However, $D S M-I V$ was criticized because the diagnostic criteria for ADHD were primarily focused on children, which leads to underdiagnosis of many teens and adults with symptoms of ADHD (APA, 1994; Applegate et al., 1997). In 2013, Diagnostic and Statistical Manual of Mental Disorders (5th ed.; DSM-5; APA, 2013) was updated according to the evidence of the reduction in symptoms with increasing age. Adults as well as teens can now be diagnosed more easily because $D S M-5$ raises the age limit of when symptoms should be documented, that is, from age 7 to age 12 and lowers the number of symptoms from 6 to 5 for diagnosis in individuals of age 17 and above (APA, 2013). With the implementation of $D S M-5$, the prevalence of adult ADHD after 2013 will be expected to be higher from what has been reported (Ghanizadeh, 2013).

Second, similar to other studies, we observed a substantial increase in both the prevalence rates of ADHD diagnosis and treatment among adult Medicaid beneficiaries (Holden et al., 2013; Knight et al., 2014; McCarthy et al., 2012; Montejano et al., 2011). In this study, we observed an approximately five fold relative increase in ADHD diagnosis and a seven fold relative increase in ADHD treatment in adult patients. This substantial increase in diagnosis of ADHD in adults could partially be explained by the fact that the prevalence of ADHD may have been influenced by modified diagnostic criteria among adults over time (Wender, Wolf, \& Wasserstein, 2001). Furthermore, our findings reflect the increasing clinician and public recognition of ADHD as a serious medical condition for adults and 


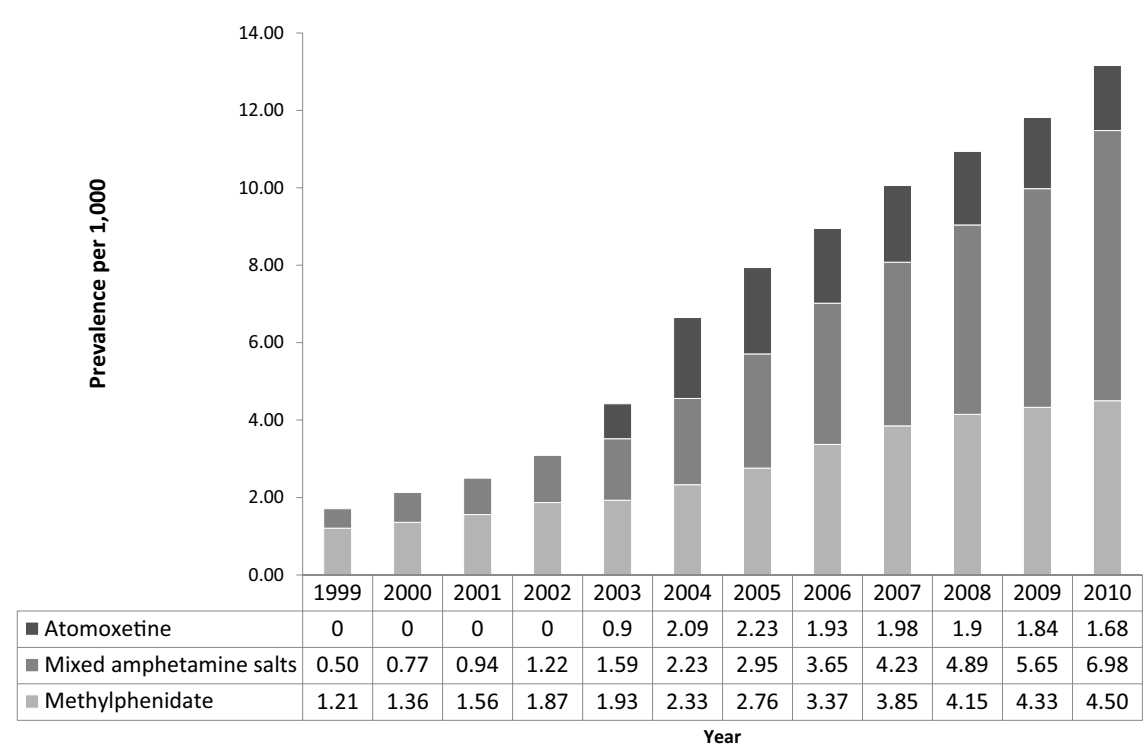

Figure 5. Annual prevalence of methylphenidate, mixed amphetamine salts, and atomoxetine preparations use.

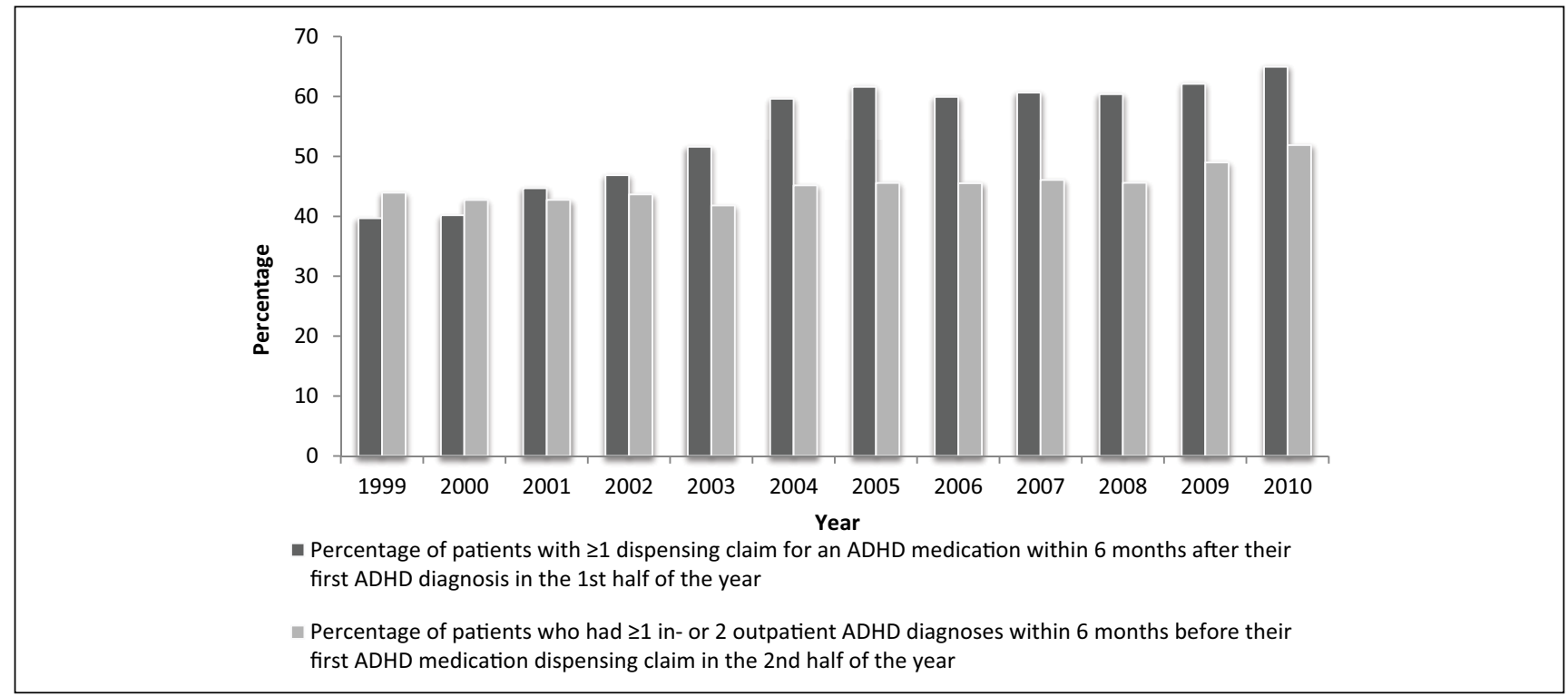

Figure 6. Percentage of patients with ADHD medication after ADHD diagnosis and percentage of patients who had ADHD diagnosis before ADHD medication.

also raise concerns about the potential growth of the medical and economic burden related to ADHD in adults, especially in patients with low social economic status. In terms of prevalence of specific drug classes, mixed amphetamine salts had surpassed methylphenidate utilization at the end of the study period, where the prevalence of mixed amphetamine salts was one and a half times as large as the prevalence of methylphenidate. Atomoxetine use was on the decline across all 29 states with marginal prevalence rates in 2010. The fluctuation of the prevalence of atomoxetine use corresponds with the box warning issued by the Food and Drug Administration (FDA) for the potential side effect related to suicidal behavior/ideation in September 2005.

Third, the growth of ADHD diagnosis and treatment occurred across both genders and all age groups over the 12-year study period. Compared with males, the prevalence of both diagnosis and treatment among females was lower, which were similar to what has been observed in children (Winterstein et al., 2008). However, the prevalence in females increased slightly faster than that in males. Compared with 
older age groups, the highest prevalence in 18 to 25 age group can be explained by delayed diagnosis from childhood, persistence of ADHD from childhood, as well as the increased recognition and diagnosis of ADHD in the college-age population. Some argue that the lower prevalence in older age groups could also be explained by improvement of hyperactivity and impulsivity and increased compensation strategies over time (Biederman, Wilens, Spencer, \& Adler, 2007; Jackson \& Farrugia, 1997; Klein et al., 2012). However, according to survey-based studies using validated diagnostic tools, the prevalence of ADHD was estimated to be more than $3 \%$ among older adults (aged $>55$ ), which is much higher than the prevalence we observed (de Zwaan et al., 2012; Goodman, Mitchell, Rhodewalt, \& Surman, 2016; Guldberg-Kjär \& Johansson, 2009; Michielsen et al., 2012). This suggests the relative absence of diagnosis and treatment of ADHD in patients above age 55 is much likely a reflection of lack of clinician training, appropriate symptom definitions, and diagnostic tools for use among older adults in clinical practice.

Finally, the annual prevalence of ADHD treatment use surpassed the ADHD prevalence in the later study years. Following the observation, about half of the patients who had ADHD treatment did not have a service claim with a diagnosis of 314.xx within 6 months before the pharmacy to dispense claim, which could be explained by a few possible reasons. First, studies have shown that physicians may be reluctant to label adult patients with psychiatric disorders without confirming the condition (Mitchell, 2007). ADHD medications are likely to be prescribed when a clinician is unsure of the diagnosis and uses the medication response as a clinical indicator of the condition, which may result in treatment without ADHD diagnosis. In addition, with only two diagnoses that are documented with an outpatient visit claim, it is conceivable that more prominent or more acute diagnoses took precedence, and thus, ADHD may have been present but not documented. On the contrary, ADHD medications may be prescribed for narcolepsy or off-label indications such as treatment-refractory depression, cancer fatigue, obesity, or other conditions symptomatic with a lack of motivation and apathy (Greenhill et al., 2002; Jeffers \& Benotsch, 2014; Trenque, Herlem, Abou Taam, \& Drame, 2014). Given that previous studies reported prevalent nonmedical use and misuse of prescription stimulants among young adults (Kaye \& Darke, 2012; McCabe, Knight, Teter, \& Wechsler, 2005; Wilens et al., 2008), future research should address what alternative indications or purposes for ADHD medication use exist in this population.

\section{Limitation}

Our study is subject to a few limitations. In this study, we used ICD-9-CM diagnosis codes to identify ADHD diagnosis in medical encounter billing records, which has inherent limitations due to coding and billing errors. In addition, the accuracy of ADHD diagnosis depends on a number of factors, including clinician training and experience, time necessary for adequate evaluation of patients' condition, as well as outside informants to increase specificity and sensitivity of diagnosis (Asherson et al., 2010; Moncrieff \& Timimi, 2010; Surman \& Goodman, 2017). Thus, our prevalence estimate of ADHD diagnosis may not reflect the true prevalence among adults. Furthermore, we included patients from 29 states in the United States, representing the vast majority of patients enrolled in Medicaid FFS plans nationally. We did not examine the prevalence in individual states and given demonstrated variability of ADHD diagnoses and treatment across states in children (Visser et al., 2015; Visser et al., 2014), we caution against extrapolating our results to individual states. Of note, sample sizes dropped drastically in the year 2006 because of increasing Medicaid managed care penetration and decreased number of FFS enrollees (Centers for Medicare \& Medicaid Services, 2013). In the present analysis, we restricted eligible beneficiaries to those in FFS or PCCM plans from 1999 to 2010 with no supplemental managed care plan other than dental because of concerns on completeness and quality of the encounter data of managed care plan. Thus, our results may have limited generalizability to Medicaid patients in other managed care plans.

\section{Conclusion}

In summary, this study reports the prevalence estimates of ADHD diagnosis and treatment using administrative data in Medicaid Analytic eXtract (MAX) billing records. The prevalence of adult ADHD diagnosis and medication use has increased substantially from 1999 to 2010 across both genders and all age groups. Approximately, half of the patients did not have a prescription claim within 6 months of the diagnosis whereas half of the patients on ADHD medications did not have a diagnosis 6 months before the treatment. These findings on ADHD diagnosis and treatment emphasize the need for studies that examine the treatment patterns of Adult ADHD and alternative diagnosis and purpose of ADHD medication use.

\section{Authors' Note}

The results in this study have been presented at the $31 \mathrm{st}$ International Conference on Pharmacoepidemiology \& Therapeutic Risk Management in Boston, 2015. The second author, Dr. Liu, is currently an employee of the U.S. Food and Drug Administration (FDA). Dr. Liu was involved in this study while he was a postdoctoral associate at the University of Florida. The views expressed in this article are those of the authors and not necessarily those of the FDA. 


\section{Declaration of Conflicting Interests}

The author(s) declared no potential conflicts of interest with respect to the research, authorship, and/or publication of this article.

\section{Funding}

The author(s) disclosed receipt of the following financial support for the research, authorship, and/or publication of this article: Financial support for this study was provided by the Florida Agency for Health Care Administration (Contract No. MED152).

\section{References}

Almeida Montes, L. G., Hernández García, A. O., \& RicardoGarcell, J. (2007). ADHD prevalence in adult outpatients with nonpsychotic psychiatric illnesses. Journal of Attention Disorders, 11, 150-156. doi:10.1177/1087054707304428

American Psychiatric Association. (1994). Diagnostic and statistical manual of mental disorders (4th ed.). Washington, DC: Author.

American Psychiatric Association. (2013). Diagnostic and statistical manual of mental disorders (5th ed.). Arlington, VA: American Psychiatric Publishing.

Applegate, B., Lahey, B. B., Hart, E. L., Biederman, J., Hynd, G. W., Barkley, R. A., . . . Shaffer, D. (1997). Validity of the age-of-onset criterion for ADHD: A report from the DSM-IV field trials. Journal of the American Academy of Child \& Adolescent Psychiatry, 36, 1211-1221.

Asherson, P., Adamou, M., Bolea, B., Muller, U., Morua, S. D., Pitts, M., ... Young, S. (2010). Is ADHD a valid diagnosis in adults? Yes. British Medical Journal, 340, Article c549.

Barry, C. L., Martin, A., \& Busch, S. H. (2012). ADHD medication use following FDA risk warnings. Journal of Mental Health Policy and Economics, 15, 119-125.

Biederman, J., Wilens, T., Spencer, T., \& Adler, L. (2007). Diagnosis and treatment of adults with attention-deficit/ hyperactivity disorder. CNS Spectrums, 12(4), A1-A14.

Castle, L., Aubert, R. E., Verbrugge, R. R., Khalid, M., \& Epstein, R. S. (2007). Trends in medication treatment for ADHD. Journal of Attention Disorders, 10, 335-342. doi:10.1177/1087054707299597

Centers for Medicare \& Medicaid Services. (2013). 2013 Medicaid managed care enrollment report. Retrieved from https://www.medicaid.gov/medicaid-chip-program-information/by-topics/data-and-systems/medicaid-managed-care/ downloads/2013-managed-care-enrollment-report.pdf

Davidson, M. A. (2008). ADHD in adults: A review of the literature. Journal of Attention Disorders, 11, 628-641. doi: $10.1177 / 1087054707310878$

de Zwaan, M., Gruss, B., Müller, A., Graap, H., Martin, A., Glaesmer, H., . . . Philipsen, A. (2012). The estimated prevalence and correlates of adult ADHD in a German community sample. European Archives of Psychiatry \& Clinical Neurosciences, 262, 79-86. doi:10.1007/s00406-011-0211-9

Faraone, S. V., \& Biederman, J. (2005). What is the prevalence of adult ADHD? Results of a population screen of 966 adults. Journal of Attention Disorders, 9, 384-391. doi:10.1177/1087054705281478
Ghanizadeh, A. (2013). Agreement between Diagnostic and Statistical Manual of Mental Disorders, Fourth Edition, and the proposed DSM-V attention deficit hyperactivity disorder diagnostic criteria: An exploratory study. Comprehensive Psychiatry, 54, 7-10. doi:10.1016/j.comppsych.2012.06.001

Goldman, L. S., Genel, M., Bezman, R. J., \& Slanetz, P. J. (1998). Diagnosis and treatment of attention-deficit/hyperactivity disorder in children and adolescents. Council on Scientific Affairs, American Medical Association. Journal of the American Medical Association, 279, 1100-1107.

Goodman, D. W., Mitchell, S., Rhodewalt, L., \& Surman, C. B. (2016). Clinical presentation, diagnosis and treatment of attention-deficit hyperactivity disorder (ADHD) in older adults: A review of the evidence and its implications for clinical care. Drugs \& Aging, 33, 27-36. doi:10.1007/s40266-015-0327-0

Greenhill, L. L., Pliszka, S., Dulcan, M. K., Bernet, W., Arnold, V., \& Beitchman, J., . . . American Academy of Child and Adolescent Psychiatry. (2002). Practice parameter for the use of stimulant medications in the treatment of children, adolescents, and adults. Journal of the American Academy of Child \& Adolescent Psychiatry, 41(2 Suppl.), 26S-49S.

Guldberg-Kjär, T., \& Johansson, B. (2009). Old people reporting childhood AD/HD symptoms: Retrospectively self-rated $\mathrm{AD} / \mathrm{HD}$ symptoms in a population-based Swedish sample aged 65-80. Nordic Journal of Psychiatry, 63, 375-382. doi:10.1080/08039480902818238

Heiligenstein, E., Conyers, L. M., Berns, A. R., Miller, M. A., \& Smith, M. A. (1998). Preliminary normative data on DSM-IV attention deficit hyperactivity disorder in college students. Journal of American College Health, 46, 185-188. doi: 10.1080/07448489809595609

Holden, S. E., Jenkins-Jones, S., Poole, C. D., Morgan, C. L., Coghill, D., \& Currie, C. J. (2013). The prevalence and incidence, resource use and financial costs of treating people with attention deficit/hyperactivity disorder (ADHD) in the United Kingdom (1998 to 2010). Child and Adolescent Psychiatry and Mental Health, 7, Article 34. doi:10.1186/1753-2000-7-34

Hudson, C. G. (2005). Socioeconomic status and mental illness: Tests of the social causation and selection hypotheses. American Journal of Orthopsychiatry, 75, 3-18. doi:10.1037/ 0002-9432.75.1.3

Jackson, B., \& Farrugia, D. (1997). Diagnosis and treatment of adults with attention deficit hyperactivity disorder. Journal of Counseling \& Development, 75, 312-319.

Jeffers, A. J., \& Benotsch, E. G. (2014). Non-medical use of prescription stimulants for weight loss, disordered eating, and body image. Eating Behaviors, 15, 414-418. doi:10.1016/j. eatbeh.2014.04.019

Johansen, M. E., Matic, K., \& McAlearney, A. S. (2015). Attention deficit hyperactivity disorder medication use among teens and young adults. Journal of Adolescent Health, 57, 192-197. doi:10.1016/j.jadohealth.2015.04.009

Kaye, S., \& Darke, S. (2012). The diversion and misuse of pharmaceutical stimulants: What do we know and why should we care? Addiction, 107, 467-477. doi:10.1111/j.13600443.2011.03720.x

Kessler, R. C., Adler, L., Barkley, R., Biederman, J., Conners, C. K., Demler, O., . . Z Zaslavsky, A. M. (2006). The prevalence and 
correlates of adult ADHD in the United States: Results from the National Comorbidity Survey Replication. American Journal of Psychiatry, 163, 716-723. doi:10.1176/ajp.2006.163.4.716

Klein, R. G., Mannuzza, S., Olazagasti, M. A., Roizen, E., Hutchison, J. A., Lashua, E. C., \& Castellanos, F. X. (2012). Clinical and functional outcome of childhood attention-deficit/hyperactivity disorder 33 years later. Archives of General Psychiatry, 69, 1295-1303. doi:10.1001/archgenpsychiatry.2012.271

Knight, T. K., Kawatkar, A., Hodgkins, P., Moss, R., Chu, L. H., Sikirica, V., . . . Nichol, M. B. (2014). Prevalence and incidence of adult attention deficit/hyperactivity disorder in a large managed care population. Current Medical Research \& Opinion, 30, 1291-1299. doi:10.1185/03007995.2014.901940

Lara, C., Fayyad, J., de Graaf, R., Kessler, R. C., Aguilar-Gaxiola, S., Angermeyer, M., . . . Sampson, N. (2009). Childhood predictors of adult attention-deficit/hyperactivity disorder: Results from the World Health Organization World Mental Health Survey Initiative. Biological Psychiatry, 65, 46-54. doi:10.1016/j.biopsych.2008.10.005

Mannuzza, S., Klein, R. G., \& Moulton, J. L. (2003). Persistence of attention-deficit/hyperactivity disorder into adulthood: What have we learned from the prospective follow-up studies? Journal of Attention Disorders, 7, 93-100.

McCabe, S. E., Knight, J. R., Teter, C. J., \& Wechsler, H. (2005). Non-medical use of prescription stimulants among US college students: Prevalence and correlates from a national survey. Addiction, 100, 96-106. doi:10.1111/j.1360-0443.2005.00944.x

McCarthy, S., Asherson, P., Coghill, D., Hollis, C., Murray, M., Potts, L., . . . Wong, I. C. (2009). Attention-deficit hyperactivity disorder: Treatment discontinuation in adolescents and young adults. British Journal of Psychiatry, 194, 273-277. doi:10.1192/bjp.bp.107.045245

McCarthy, S., Wilton, L., Murray, M. L., Hodgkins, P., Asherson, P., \& Wong, I. C. (2012). The epidemiology of pharmacologically treated attention deficit hyperactivity disorder (ADHD) in children, adolescents and adults in UK primary care. BMC Pediatrics, 12, 78. doi:10.1186/1471-2431-12-78

Michielsen, M., Semeijn, E., Comijs, H. C., van de Ven, P., Beekman, A. T., Deeg, D. J., \& Kooij, J. J. (2012). Prevalence of attention-deficit hyperactivity disorder in older adults in The Netherlands. British Journal of Psychiatry, 201, 298-305. doi:10.1192/bjp.bp.111.101196

Miech, R., Caspi, A., Moffitt, T., Wright, B., \& Silva, P. (1999). Low socioeconomic status and mental disorders: A longitudinal study of selection and causation during young adulthood. American Journal of Sociology, 104, 1096-1131. doi:10.1086/210137

Mitchell, A. J. (2007). Reluctance to disclose difficult diagnoses: A narrative review comparing communication by psychiatrists and oncologists. Support Care Cancer, 15, 819-828. doi:10.1007/s00520-007-0226-y

Moncrieff, J., \& Timimi, S. (2010). Is ADHD a valid diagnosis in adults? No. British Medical Journal, 340, Article c547.

Montejano, L., Sasané, R., Hodgkins, P., Russo, L., \& Huse, D. (2011). Adult ADHD: Prevalence of diagnosis in a US population with employer health insurance. Current Medical Research \& Opinion, 27(Suppl. 2), 5-11. doi:10.1185/0300 7995.2011 .603302
Pary, R., Lewis, S., Matuschka, P. R., Rudzinskiy, P., Safi, M., \& Lippmann, S. (2002). Attention deficit disorder in adults. Annals of Clinical Psychiatry, 14, 105-111.

Silver, L. B. (2000). Attention-deficit/hyperactivity disorder in adult life. Child \& Adolescent Psychiatric Clinics of North America, 9, 511-523.

Simon, V., Czobor, P., Bálint, S., Mészáros, A., \& Bitter, I. (2009). Prevalence and correlates of adult attention-deficit hyperactivity disorder: Meta-analysis. British Journal of Psychiatry, 194, 204-211. doi:10.1192/bjp.bp.107.048827

Surman, C. B., \& Goodman, D. W. (2017). Is ADHD a valid diagnosis in older adults? ADHD Attention Deficit and Hyperactivity Disorder. Advance online publication. doi:10.1007/s12402017-0217-x

Trenque, T., Herlem, E., Abou Taam, M., \& Drame, M. (2014). Methylphenidate off-label use and safety. SpringerPlus, 3, Article 286. doi:10.1186/2193-1801-3-286

Visser, S. N., Bitsko, R. H., Danielson, M. L., Ghandour, R. M., Blumberg, S. J., Schieve, L. A., . . . Cuffe, S. P. (2015). Treatment of attention deficit/hyperactivity disorder among children with special health care needs. Journal of Pediatrics, 166, 1423-1430.e1421-1422. doi:10.1016/j. jpeds.2015.02.018

Visser, S. N., Danielson, M. L., Bitsko, R. H., Holbrook, J. R., Kogan, M. D., Ghandour, R. M., . . Blumberg, S. J. (2014). Trends in the parent-report of health care provider-diagnosed and medicated attention-deficit/hyperactivity disorder: United States, 20032011. Journal of the American Academy of Child \& Adolescent Psychiatry, 53, 34-46.e32. doi:10.1016/j.jaac.2013.09.001

Volkow, N. D., \& Swanson, J. M. (2013). Clinical practice: Adult attention deficit-hyperactivity disorder. New England Journal of Medicine, 369, 1935-1944. doi:10.1056/ NEJMcp1212625

Wender, P. H., Wolf, L. E., \& Wasserstein, J. (2001). Adults with ADHD. An overview. Annals of the New York Academy of Sciences, 931, 1-16.

Wilens, T. E., Adler, L. A., Adams, J., Sgambati, S., Rotrosen, J., Sawtelle, R., . . .Fusillo, S. (2008). Misuse and diversion of stimulants prescribed for ADHD: A systematic review of the literature. Journal of the American Academy of Child \& Adolescent Psychiatry, 47, 21-31. doi:10.1097/ chi.0b013e31815a56f1

Winterstein, A. G., Gerhard, T., Shuster, J., Zito, J., Johnson, M., Liu, H., \& Saidi, A. (2008). Utilization of pharmacologic treatment in youths with attention deficit/hyperactivity disorder in Medicaid database. Annals of Pharmacotherapy, 42, 24-31. doi:10.1345/aph.1K143

\section{Author Biographies}

Yanmin Zhu, BA, is a $\mathrm{PhD}$ graduate student studying pharmacoepidemiology in the Department of Pharmaceutical Outcomes and Policy at the University of Florida. Her current research focuses on the utilization and outcomes of psychoactive medications, with a particular interest in pregnant and pediatric populations.

Wei Liu, MS, PhD, MD, is currently an epidemiologist at the U.S. Food and Drug Administration. His research involves the utilization of large linked data resources to study drug prescription patterns and postmarketing surveillance of adverse drug reactions. 
Yan Li, MS, is a PhD graduate student studying pharmacoepidemiology in the Department of Pharmaceutical Outcomes and Policy at the University of Florida. His current research focuses on examining pain management and prescription drug abuse.

Xi Wang, MPH, is a $\mathrm{PhD}$ graduate student in the Department of Pharmaceutical Outcomes and Policy at the University of Florida. Her current research focuses on generating evidence for the comparative safety of drug treatments for children, adolescents and pregnant women. She has a special interest in applied large observational research to address questions that are unanswerable in clinical trials.

Almut G. Winterstein, RPh, $\mathrm{PhD}$, FISPE, holds the position of professor and chair in the Department of Pharmaceutical Outcomes and Policy at the College of Pharmacy, and an affiliate appointment in the Department of Epidemiology at the Colleges of Public Health and Health Professions and Medicine, University of Florida. Dr. Winterstein's research interests focus on drug safety and effectiveness of approved drug products, and the evaluation and improvement of medication use. 